\title{
The Qualities of Architecture in Relation to Universal Design
}

\author{
Carolyn AHMER ${ }^{1}$ \\ Western Norway University of Applied Sciences
}

\begin{abstract}
Aesthetic experience of the built environment involves all our senses: the sight of colour and form; the echo in a room; the smell of wood; the touch of handrails; the refreshing cool air on the skin, and so on. However, the definition of universal design sets no criteria for aesthetics, only stating the functional requirements that need to be met. The term for many architects and planners is still too closely associated with legislations, regulations, and standards. Buildings designed by some of the pioneers of modern architecture have been briefly mentioned in relation to universal design: Le Corbusier and Frank Lloyd Wright's use of the ramp as an architectural element, Mies van der Rohe's plans, the fluent transition between inside and outside, through which people may move easily and effortlessly, and Alvar Aalto's design of details, such as door handles suitable for people of varying heights. However, their architectural works have greater potential as sources of inspiration with respect to moving buildings in a universal direction. Rem Koolhaas' innovative design for a client with reduced mobility and his library projects are examples of how a contemporary architect has used Le Corbusier's architecture as a source of reference. This paper refers to or includes works made by the above-mentioned architects to illustrate universal design and thereby discusses architectural qualities and aesthetics in relation to the needs of people with reduced mobility, vision and hearing.
\end{abstract}

Keywords. Universal design; architecture; aesthetics; senses

\section{Introduction}

The history of architecture reflects changes in society, politics and stylistic trends. Universal design, for instance, is a term that was unfamiliar to most architects in the twentieth century. The American architect Ronald L. Mace coined the term universal design in 1985 to describe the concept of designing all products and the built environment to be aesthetic and usable to the greatest extent possible by everyone, regardless of their age, ability, or status in life [1]. Aesthetics comes from the Greek word aisthēsis, referring to sensory perception and understanding, or sensuous knowledge. Aesthetic experience of the built environment involves all our senses: the sight of color and form; the echo in a room; the smell of wood; the touch of handrails; the refreshing cool air on the skin, and so on. The definition of universal design sets no criteria for

${ }^{1}$ Corresponding Author: Carolyn Ahmer, Associate Professor, Dr. ing. E-mail: cah@hvl.no. 
aesthetics, only on the functional requirements that need to be met. The Convention on the Rights of Persons with Disabilities (2006) defines universal design as the design of products, environments, programs, and services to be usable by all people, to the greatest extent possible, without the need for adaptation or specialized design [2]. The challenge today lies in designing buildings and outdoor areas that do more than just fulfil regulatory requirements, and that stand out as universal from a conceptual, functional, spatial, and material perspective.

Buildings designed by some of the pioneers of modern architecture have been briefly mentioned in relation to universal design: Le Corbusier and Frank Lloyd Wright's use of the ramp as an architectural element, Mies van der Rohe's plans, the fluent transition between inside and outside, through which people may move easily and effortlessly, and Alvar Aalto's design of details, such as door handles suitable for people of varying heights [3]. However, their architectural works have greater potential as sources of inspiration with respect to moving buildings in a universal direction. Rem Koolhaas' innovative design for a client with reduced mobility and his library projects are examples of how a contemporary architect has used Le Corbusier's architecture as a source of reference.

This paper which is based on literature- and document studies, refers to or includes works made by the above-mentioned architects to illustrate universal design and thereby discusses architectural qualities and aesthetics in relation to the needs of people with reduced mobility, vision and hearing. In this context Gunnar Asplund's use of contrast (given by color, texture, size, shape) and James Stirling's architectural promenade, is of interest. The aim has been to identify and highlight the qualities of architectural design that are essential to experiencing and creating buildings that stimulates our senses.

\section{Designing for Clients with Reduced Mobility}

In "An Open Letter to Architects" (1987), the architect Raymond Lifchez stresses that "accessibility is more than a matter of admittance or logistics; it is also a quality of experience. How one feels about a place, how one interprets it, or even whether one can adequately interpret it - these are all less quantifiable, but crucially important, aspects of accessibility" [4].

\subsection{A Pioneering Project}

Laurent House (1952), designed by the American architect Frank Lloyd Wright, and the Maison à Bordeaux (1998), designed by the Dutch architect Rem Koolhaas, are both manifestations of Lifchez' assertion. In both houses, human movement was a crucial factor which influenced the whole layout of the building, from inside to outside.

Wright designed a wheelchair-accessible home, decades before the first draft of the Americans with Disabilities Act (1990) was ever presented (Figure 1). Kenneth Laurent, a World War II veteran with a mobility impairment, had written a letter to Wright where he explained his need for a practical and sensible home, qualities he had seen in one of Wright's Usonian houses, pictured in the magazine House Beautiful. The Usonian houses are single-story dwellings with fireplaces and central heating, characterized by regional materials, flat roofs with overhangs, chimneys and carports. The houses are often Lshaped to fit around a garden terrace, a layout that makes it easy to move between the indoor and outdoor areas. In designing the house for Laurent, Wright adjusted his Lshaped Usonian house to a "hemicycle Usonian". He adapted the house to the needs of 
his client: wider doorways were added to make the home wheelchair-accessible, and doorknobs were placed at a lower level than usual. Since his client had problems with opening the drawers of bureaus or desks, Wright designed built-in cabinets with doors that fold down on hinges and make it easy to reach into the spaces within them. The bathroom, which was quite spacious for the time, includes a low-step shower and a rollunder sink. Throughout the house, the seating was created so that guests would sit at eyelevel with his client. Wright referred to this house, a more compact and organic layout than his Usonian houses, as "my little gem".

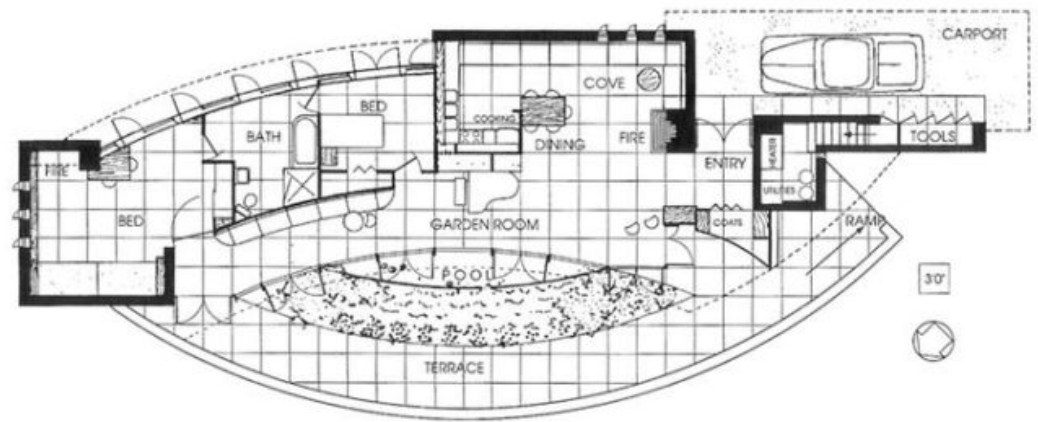

Figure 1. Frank Lloyd Wright. Floor plan of Laurent house. A hemicycle Usonian. Public domain.

Wright's Guggenheim museum of 1955 in New York is designed around a spiralling inner ramp. He may well have been inspired by his dialogue with Laurent, with whom he developed a life-long friendship. Unlike many ramps from this period, which are quite steep, the slope of the inner ramp in the museum is so slight that the wall along it is used to exhibit paintings.

\subsection{A Complex House that Defines My World}

Completed in 1998, Maison Bordeaux is situated on a small, cape-like hill overlooking the city of Bordeaux. The house was designed for a couple and their family by Koolhaas. Despite having been paralyzed by a life-threatening car accident, the man did not want a straightforward house. Rather, he wanted a complex design: "Contrary to what you would expect. I want a complex house because the house will define my world" [5]. Koolhaas proposed a house with three volumes stacked on top of one another, each with their own unique characteristics and spatial environment. In this spatially complex house, the volumes are tied together by a central elevator platform that moves between the floors (Figure 2). The elevator, which is about $10 \mathrm{~m}^{2}$ in size, functions as the husband's office, and provides access to the entire house, from the kitchen on the lowest level to the bedroom at the top. The elevator is driven by a large hydraulic piston that raises and lowers the office whenever necessary. This innovative idea of creating a room that is capable of moving vertically through the house, creates a spatial dynamism within the house that is always changing and redefining the space of the office as well as the space where it stops. 


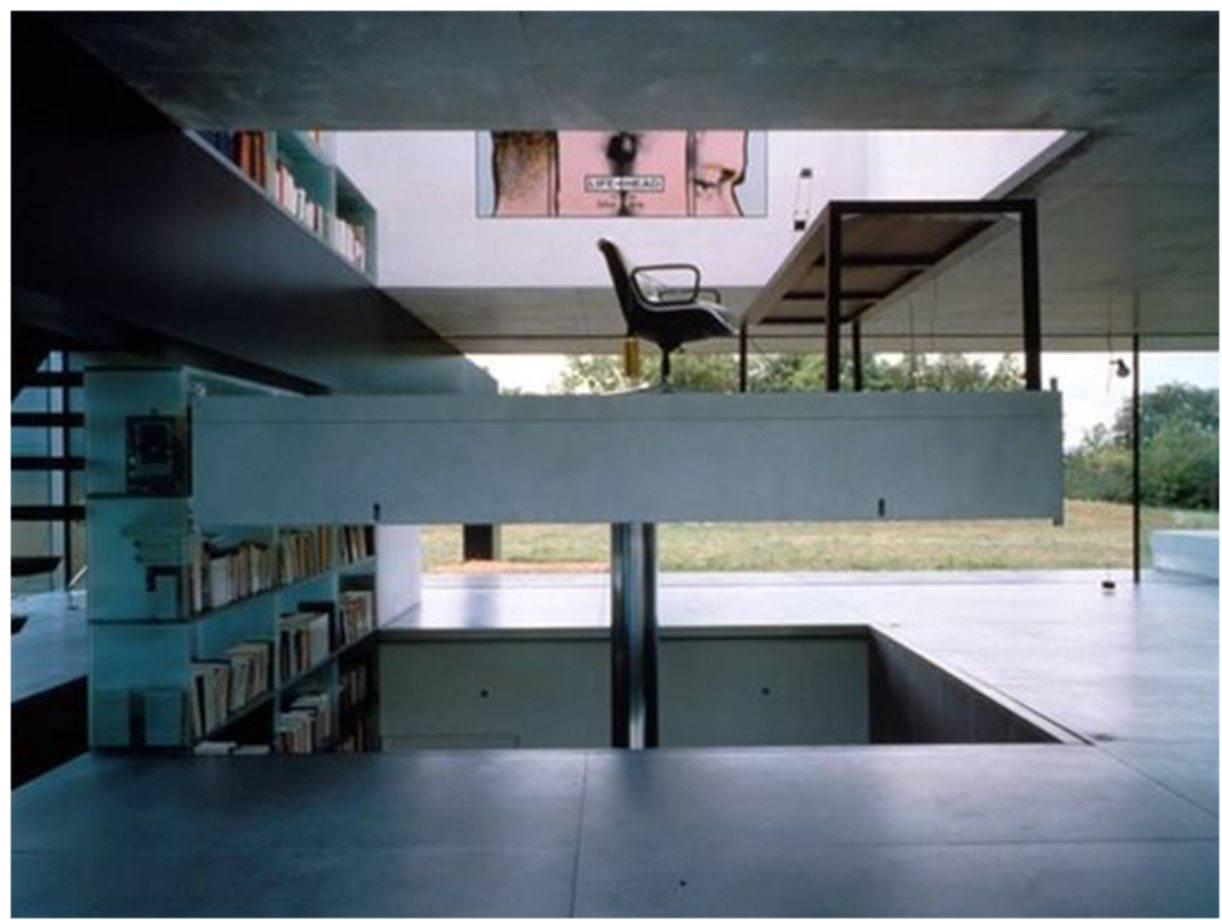

Figure 2. Rem Koolhaas. The Maison à Bordeaux. An office that moves vertically. Photo: Hans Werlemann.

The Maison Bordeaux is a masterful innovation in spatial design that exceeded the expectations of the clients, and an innovative architectural landmark that manifests Le Corbusier's concept of the house as "a machine for living" [5]. In this house the constituents of architecture: structure: form, space, light, colors and materials interact and communicate with the senses. The fact that accessible and universal design can be an innovative strategy that influences the whole layout and form of the building shows that it is possible to move away from specialization, not only in terms of use, but also in the expression of the form.

\section{Visual and Non-visual Information}

"We use totality. That is what we use first, and that is what gives meaning to the details," proclaimed the Norwegian architect Christian Norberg-Schulz [6]. Visual composition in architectural design is about the syntactical relationship between individual parts, and between the individual parts and the whole. People with "normal" vision first perceive the totality of the room and then the individual elements within it. For the visually impaired the process is the opposite-individual elements are perceived first, and then a perception is formed of how the individual elements are linked together. Their ability to perceive the totality will depend on the clarity, created by the contrasts and lighting, and how complex the visual image is [7]. Visual elements can be texture, color, tone, solids and voids and form, shape and direction. Corridors, ramps and stairs are examples of architectural elements that give direction. Wayfinding by the articulation of these 
elements and lighting can facilitate the perception of, and orientation in, space for people with reduced vision and hearing.

\subsection{Contrasts that Make Shape or Form Visible}

For the visually impaired, who use whatever vision they have to orientate themselves, visual contrast is important, while tactile contrast or the surface structure of materials is used as a supplement. Color composition and contrast can make the shape of a room more visible and accentuate different functions, building elements, and other details. However, while it is a common misunderstanding that the blind and visually impaired need strong colors, different tones are essential [7]. "If you half close your eyes and look about you [...] it becomes quite evident how much we rely upon tonal variation both for the identification of what we see, and as an element of composition" [8]. A contrast can be both a color contrast and a luminance contrast (gray-tone contrast). Color contrast affects what people see because colors also contain codes used in our surroundings. The luminance contrast, which is associated with our ability to perceive depth and movement, is essential for seeing in three dimensions [9].

The Woodland Chapel (1920) at the Woodland Cemetery in Stockholm, by the Swedish architect Gunnar Asplund, illustrates how architectural design can help visitors navigate space (Figure 3). Outside, the contrasts between the grayish white of the walls and the black shingles of the roof, make the form and entrance visible from a distance.

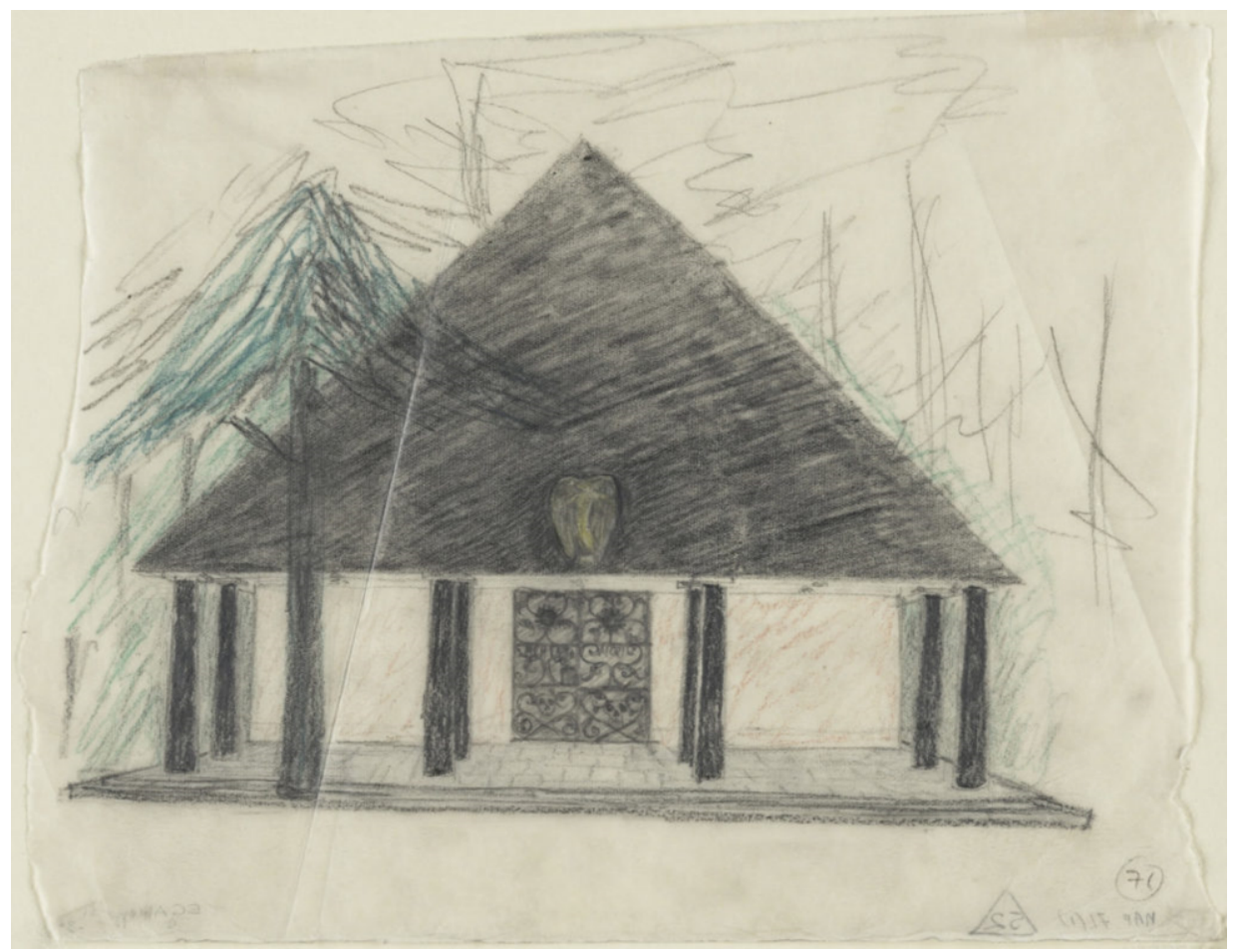

Figure 3. Gunnar Asplund. Woodland Chapel. Sketch: front perspective. Public domain. 
In the interior Asplund used lighting effects and different surface materials to create different zones. Edges marking the points where the floor surfaces change help the mourners to perceive and understand things in the room. The chapel has a domed glass roof that sheds light on the area around the catafalque, the final resting place of the coffin, and makes the space unexpectedly bright and airy. The expression of contrast between color, textures, materials and narrow and open spaces are characteristic of Asplund's architecture in the 1920s.

\subsection{Colors, Lighting and Acoustics for Physiological Well-being}

The finish architect Alvar Aalto emphasized the importance of acknowledging patients' psychological and physiological needs as the basis for design. He paid special attention to colors, lighting and acoustics in his design of the tuberculosis sanatorium in Paimio (1929-1933). Aalto, who used colors that would soothe the patients, was very particular about the color shades, and mixed colors with black in order to reduce brightness. The ceilings in the patient rooms are painted in a grayish green in order to avoid glare. Aalto writes: "The walls are light and the ceilings darker. This makes the general tone more peaceful from the perspective of a lying-down patient. The general lighting point of the room is above the patient's head at the interface of the wall and ceiling, which means that it is outside the angle of vision of a lying-down patient" [10].

The most typical patient room, the twin room, was designed around the needs of the patients: they could look out of the window while resting and pivot bedside tables over the bed. The lighting was designed to not disturb the other patient, and the radiator installed on the ceiling emitted even, comfortable warmth. Aalto drew numerous diagrams analyzing the functions of the space and emphasizing the individual patients' privacy in a twin room by various acoustic means. For him a calm acoustic environment was as important as the lighting to the sanatorium environment. Every patient had to have his or her own wash-basin, as a basic ritual of good hygiene, which resulted in the design of a splash-free and noiseless wash-basin. Maintaining high standards of hygiene was a key ritual at a tuberculosis sanatorium, and Aalto designed furnishings that would allow immaculate hygiene. With unconventional solutions, he created a sense of individuality to enrich the everyday environment for the patients [11].

\subsection{Tactile, Audible or Aromatic Information}

The blind and the severely visually impaired will orientate themselves with the help of tactile, audible or aromatic information from their surroundings. Tactility occupies a special place in architecture since the sense of touch can identify different objects, structures, and materials. Texture and pattern can, for instance, provide sensory cues that can help to differentiate between areas and navigate space. A gravel path leading to a house, for instance, announces the visitor's steps, whereas if it is asphalted it no longer delivers its message. If the feet shall distinguish between different materials used in surfaces, the materials should provide sufficient acoustic feedback when touched by canes. The hands can feel tactile signs, materials and other forms of tactile information. Aalto's use of leather in door handles and of wood in handrails show his interest in the tactile properties of architecture (Figure 4). He designed door handles, which could be stacked at various levels to accommodate the needs of people of varying heights. The sense of smell is important for orientation as it may identify places: the smell of concrete, 
wood, leather, the smell of gardens, the smell of a fireplace, the smell of cooking and so on.

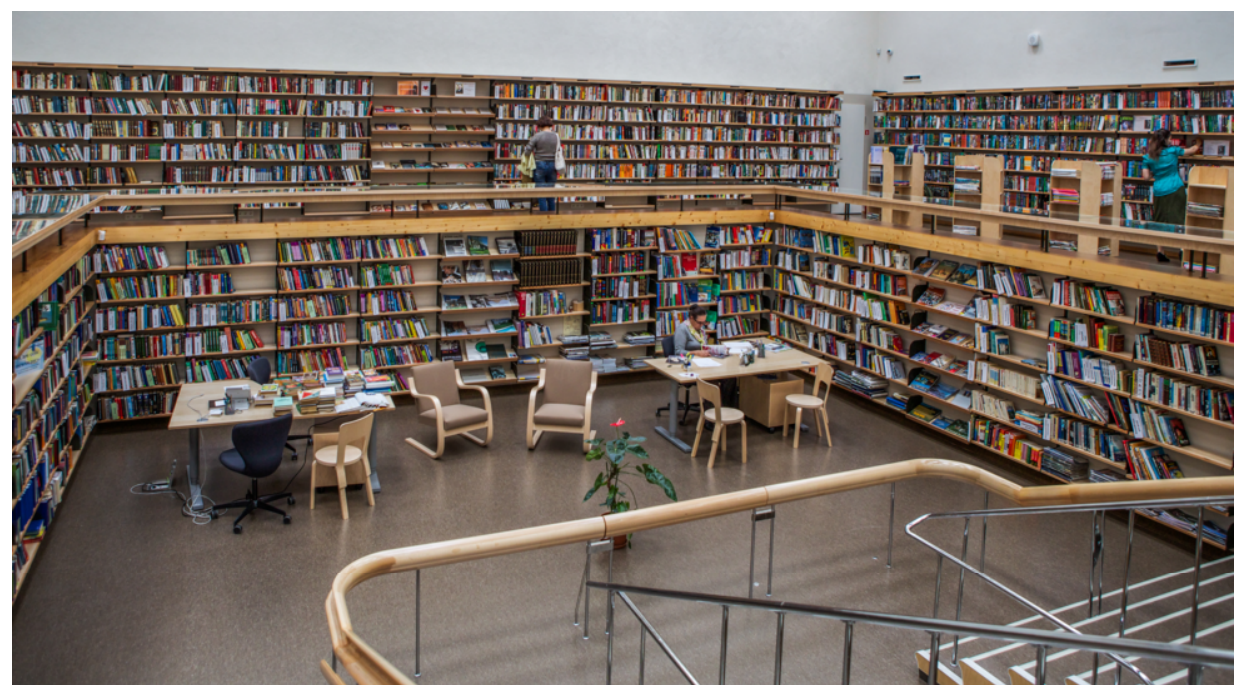

Figure 4. Alvar Aalto. Interior Vyborg City Library. Wikimedia..

The Center for Universal Design at North Carolina State University developed seven principles to guide designers and architects in creating more accessible buildings and outdoor areas. Although some architects have criticized the principles for being too focused on product design, and others have criticized them as vague, incomplete and difficult to understand, little re-evaluation, reconsideration or questioning of the principles has occurred since they were introduced in 1997 [12]. Principle 2 (flexibility in use), for instance, states that the design should accommodate a wide range of individual preferences and abilities. This problem is evident in schools with open-plan layouts and large common areas, were switching between large and small groups, and creating new groups, require joint use and multiple use- - which in turn requires flexible building systems. This may be at the expense of acoustics, orientation, concentration and affinity.

People with impaired hearing who depend on vision as their primary sense are sensitive to acoustic noise and too much waving or motion in a space. Standard lighting can also cause problems because it provides no orientation points. As the relationship between people and space is fundamental to the practice of architecture, the seven principles cannot automatically be transferred to buildings. Solutions based on the principles, which may be satisfactory in their own right, often appear removed from the rest of the structure or from their surroundings [13].

\section{Human Movement through Space}

Leon Battista Alberti, the Renaissance architectural theorist, saw houses as small towns and towns as large houses in which people move from room to room. "Within a space or 
building, between spaces and from inside to outside, human movement is a major factor and influences the whole building arrangement" [8]. In architecture, various elements mutually affect each other, and the sum of their individual contributions determines the aesthetic experience and usability of a space.

\subsection{The Relationship between Solids and Voids}

The pioneers of the modern movement in architecture were seeking a new basis of design related to a structural system. Their work shows great concern for visual compositions, not just as a visual style, but also in terms of movement and users' experience of a space. However, the extensive use of glass surfaces that characterizes modernist architecture can be challenging in bright daylight and sunshine. A survey shows that this creates the biggest problem for visually impaired people in buildings [9]. Many people with hearing impairments have to lip-read to be able to understand what is being said, and this proves difficult if the speaker is standing against a lit background. The same applies to those who are deaf and who are dependent on seeing someone using sign language.

Mies van der Rohe's German Pavilion for the International Exposition in Barcelona in 1929 is an example of "free plan", the use of a glass and steel frame to replace loadbearing walls and reduce the separation between interior and exterior spaces (Figure 5). The pavilion is an example of how Mies van der Rohe incorporates overhanging roofs and solid materials, to avoid direct sunlight and to guide direction. As the visually impaired need wall surfaces to help them navigate, the relationship between solids (materials) and voids (openings and windows) is crucial. Mies van der Rohe's pavilion consists of solid, offset wall places, which make a clear distinction between solids and voids, and gives a sense of direction and space. While narrow corridors require progressive and rapid movements, wider corridors signal that there is space for rest.

Interior design features are crucial for improving the awareness and understanding of the path system and linking interior directions to a larger orientation system. Design features assist users in orienting themselves throughout the space, from inside to outside. A sculpture, for instance, standing in the water court serves as a point of reference and enhances the pavilion's scale and spatial flow. His "promenade" has framed views that induce movement through a narrow passage that opens into a larger volume.

People with impaired vision find it hard to navigate in irregular and non-right-angled structures. Daylight, artificial lighting, and colours should be planned together with the aim of accentuating the main shapes and points of interest in the surroundings. In a complex composition like Mies van der Rohe's pavilion, the directional forces arise from his use of materials and components, the use and contrast between natural and engineered materials: marble, concrete, glass and steel and the use of water. The direction provided by the shape of the pavilion is seen in relation to the elements within the space.

People with reduced vision use their hearing to distinguish between sounds and locate and analyse them to determine movement and direction. The sound or sense of water as a wayfinding system between outer and inner spaces has great potential to provide information that would help the blind and people with severely impaired vision to negotiate space. The patients at Paimio Sanatorium were encouraged to walk outdoors, along the serpentine path in the south yard that was flanked with fountains. 


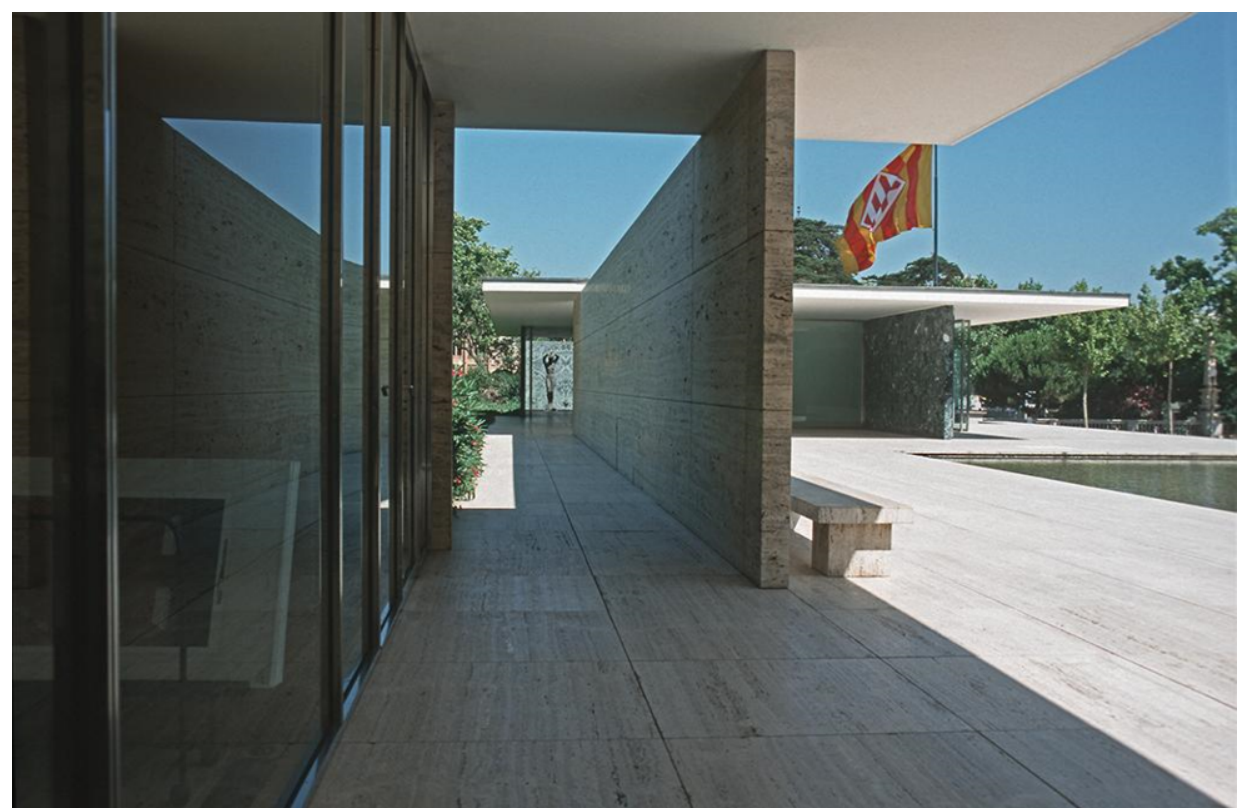

Figure 5. Mies van der Rohe. German Pavilion in Barcelona. Photo: Hans Peter Schaefer. Wikimedia.

\subsection{The Concept of the Architectural Promenade}

The ramp as an architectural promenade, the observer's pathway through the built space, is a central element in Le Corbusier's architecture [14]. The idea is that the ramp begins outside a building, continues inside it and terminates, as it often does in Le Corbusier's houses, in a roof garden. It is not the ramp in itself that is the crucial element, but it is the component that makes the promenade into an experience. As the ramp in this context is more than a circulation space, it is neither non-functional nor purely functional. Therefore, it transcends the definition of a ramp as a sloped pathway, used both inside and outside a building, to provide access between vertical levels. Wayfinding, which is the process of using spatial and environmental information to navigate in space, involves orientation and destination recognition. The architectural promenade that appeals to the senses and gives a sense of direction, a convergence of the beginning and the end, which is crucial for people with impaired vision, has great potential when it comes to universal design.

The term architectural promenade can be used in describing the work of a architects, like Koolhaas and James Stirling, both of whose designs exhibit traits of the promenade idea. In their projects, human movement is not just about the movement in and through space, but also in the alternation between movement and being stationary. In the State Gallery in Stuttgart (1984), designed by the British architect James Stirling, the ramp is used as an integrated part of the architectural design for spatial organization, circulation and sitting down. The color of the ramp's handrails gives an indication of what is next, by extending the handrails or sight line into the next area ( Figure 6). Being able to sense what is ahead can promote curiosity and exploration, and reinforce the end users' mental 
map. Most of the time those same sight lines can be used in reverse to help someone backtrack.

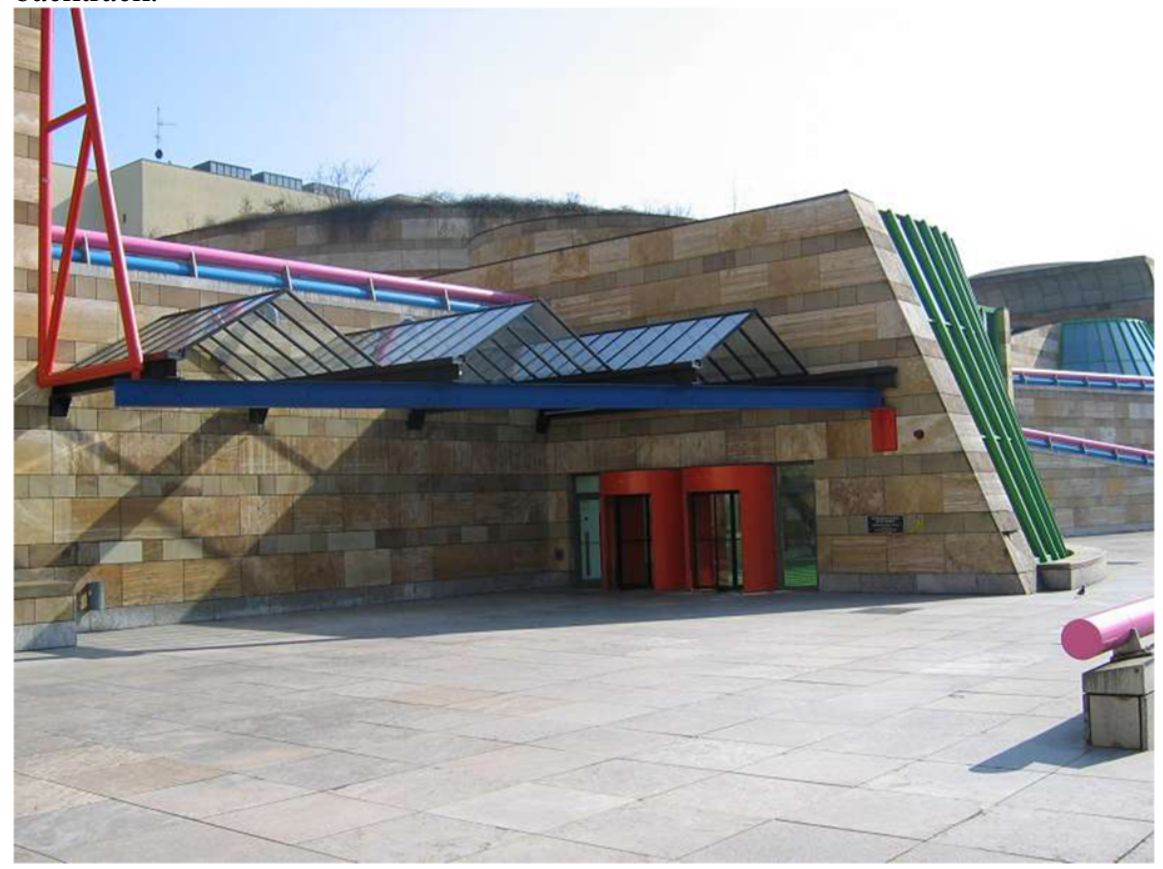

Figure 6. James Stirling. Front of the Neue Staatsgalerie Stuttgart. Wikimedia.

Koolhaas reconfigured the typical library layout in his award-winning 1992 scheme for two libraries at Jussieu, a technical university in Paris. Rather than stacking one floor on top of another, he introduced a ramp system, formed like an interior boulevard that winds its way through the entire building. Koolhaas' concept was to integrate the campus into the city, and turn the library into an urban experience [15].

In Seattle Central Library (2014), the "Books Spiral", which constitutes a major section of the building, connects four floors of bookstacks via gently sloping ramps. This allows library users to peruse the entire collection without using stairs or traveling to a different part of the building. Patrons can gather around tables amid the book spiral. The Dewey Decimal System, a library classification system that is marked on the floor, makes it possible to find any book and to return it to its proper place on the library shelves. The library reflects the social dimension of Koolhaas' work, the creation of urban meeting spaces and streets, rather than buildings and rooms. The numbers noted on the floors, for instance, create associations to numbers on houses and meeting points: "Like all big-city libraries, and perhaps more than most, the Seattle library is a hangout for the homeless and young downtowners - given Seattle's grungy dress code, it can be hard to tell them apart. Yet, everyone looks at home- the tough, no-frills interior neither patronizes nor intimidates" [16]. The library's structural system, the roughness of the materials, the polished concrete floors and the ramp as a sequence of experiences, reflects in various ways the work of Le Corbusier. 


\section{Conclusions}

The criteria for inclusive architecture should be based on both scientific and testable conditions and on experience-based criteria. Quantitative assessments aim to evaluate architecture in relation to controllable data, measurable criteria, standardized specifications and regulations. Qualitative assessments focus on features that cannot be measured, such as experiences and the sensory aesthetic experience of an architectural project.

In contemporary architecture there are many examples of architects who have understood the user needs of people with reduced functions, but the user requirements are not integrated as an integrated quality or sensory experience in their architectural design. The definition of universal design sets no aesthetic criteria, only stating the functional requirements that need to be met. Architecture that has to be developed in a universal direction must be about more than finding the best possible solution based on practical needs and technical and financial constraints.

This paper has included works made by the pioneers of modern architecture to illustrate universal design and thereby discussed architectural qualities and aesthetics in relation to the needs of people with reduced mobility, vision and hearing. The aim has been to identify and highlight the qualities of architectural design that are essential to experiencing and creating buildings that stimulates our senses. In this respect examples of architectural history can serve as a source of design inspiration for contemporary architects and designers.

\section{References}

[1] North Carolina State University. The Center for Universal Design. About the Center: Ronald L. Mace. https://projects.ncsu.edu/design/cud/about_us/usronmace.htm. Accessed 30. January 2020.

[2] Article 2. Definitions. Convention on the Rights of Persons with Disabilities, 2006. https://www.un.org/esa/socdev/enable/rights/convtexte.htm Accessed 30. January 2020.

[3] S. Asmervik, Teaching Universal Design to Students of Architecture, in: Tom Vavik (ed.) Inclusive buildings, Products \& Services, Trondheim (2009), 75-102.

[4] C. Davis \& R. Lifchez, An Open Letter to Architects, in: R. Lifchez (ed.), Rethinking Architecture: Design Students and Physically Disabled People, Berkeley, California (1987), 35-53.

[5] AD Classics: Maison Bourdeaux / OMA. Text description provided by the architects. https:/www.archdaily.com/104724/ad-classics-maison-bordeaux-oma Accessed 30. January 2020.

[6] C. Norberg-Schulz, Bruk, Byggekunst, Oslo (1991), 254.

[7] Norges Blindeforbund, Et inkluderende samfunn, Håndbok om synshemmedes krav til tilgjengelighet, Oslo, 2004.

[8] K.W. Smithies, Principles of Design in Architecture, New York, 1981.

[9] Norges Blindeforbund, Estetisk, trygt og tilgjengelig - en veileder for riktig utforming av bygg, Oslo, 2013.

[10] Alvar Aalto and the colors of the Paimio Sanatorium. Architecture 1.2.2018. Design Stories. https:/www.finnishdesignshop.com/design-stories/architecture/alvar-aalto-and-the-colors-of-thepaimio-sanatorium. Accessed 30. January 2020.

[11] M. Heikinheimo, Architecture and Technology, Alvar Altoos Paimoi Sanatorium, Aalto University publication series Doctoral dissertations 1/2016

[12] E. Björk, Many becomes losers when the Universal Design perspective is neglected: Exploring the true cost of ignoring Universal Design. Technology and Disability 21 (2009), 117-125.

[13] C. Ahmer. Making Architecture Visible to the Visual Impaired. Universal Design 2014: Three Days of Creativity and Diversity. IOS Press (2014), 204-213.

[14] Flora Samuel, Le Corbusier and the Architectural Promenade, Bale, Birkhaüser, 2010.

[15] Jussieu - Two Libraries. OMA Office Work Search. https://oma.eu/projects/jussieu-two-libraries Accessed 30. January 2020.

[16] "No one has ever described Rem Koolhaas as slow". https://www.coursehero.com/file/p5441mm/Noone-has-ever-described-Rem-Koolhaas-as-slow-The-Seattle-Central-Library/_Accessed 30. January 2020. 